Chapter 40

\title{
The Fate of Injected Water in Shale Formations
}

\author{
Hongtao Jia, John McLennan and Milind Deo \\ Additional information is available at the end of the chapter \\ http://dx.doi.org/10.5772/56443
}

\begin{abstract}
It is well known that only about a third of water injected for hydraulic fracturing of shales is recovered. It is important to understand the fate of this injected water. The amount of water infiltrating the matrix is determined by a number of parameters such as the pressure differential between the fracture and the matrix, the capillary pressure relationships in the fractures and in the matrix and other petrophysical properties of the formation. In this paper, we provide a breakdown for the various possible water losses depending on the reservoir, fracture and operating parameters. A set of capillary pressure relationships for the formation were first created based on the basic mineralogy and the total organic carbon (TOC) content. Fracture capillary pressure also changed depending on the concentrations and types of proppants in the fractures. Two basic end members can be defined - silicistic and dolomitic with different amounts of TOC. The capillary pressure relationships ranged from oil wet, neutral to water wet. Different porosity and permeability combinations were also examined. Amounts of water relative to the total amount injected that would infiltrate the formation were compiled as the operating conditions (pressures) and formation properties changed. This calculation shows that the infiltration due to the various phenomena are not sufficient to account for the water losses if the formations are strongly oil wet. In addition, situations where water blockages occur due to these multiphase flow effects were identified and the loss of productivity due to this phenomenon was quantified both for gas and for oil production. The study was conducted using a discrete-fracture network simulator developed at the University of Utah. A realistic (non-orthogonal) representation of a complex fracture network was employed in the study. Realistic representation of distribution and retention of these aqueous fracturing fluids is essential for optimizing hydraulic fracturing treatment volumes.
\end{abstract}




\section{Introduction}

The growth in producing hydrocarbons from unconventional reservoirs (shales) has been phenomenal. The production of liquids from the Eagle Ford play grew to about 52 million barrels in 2011 [1] (Figure 1).
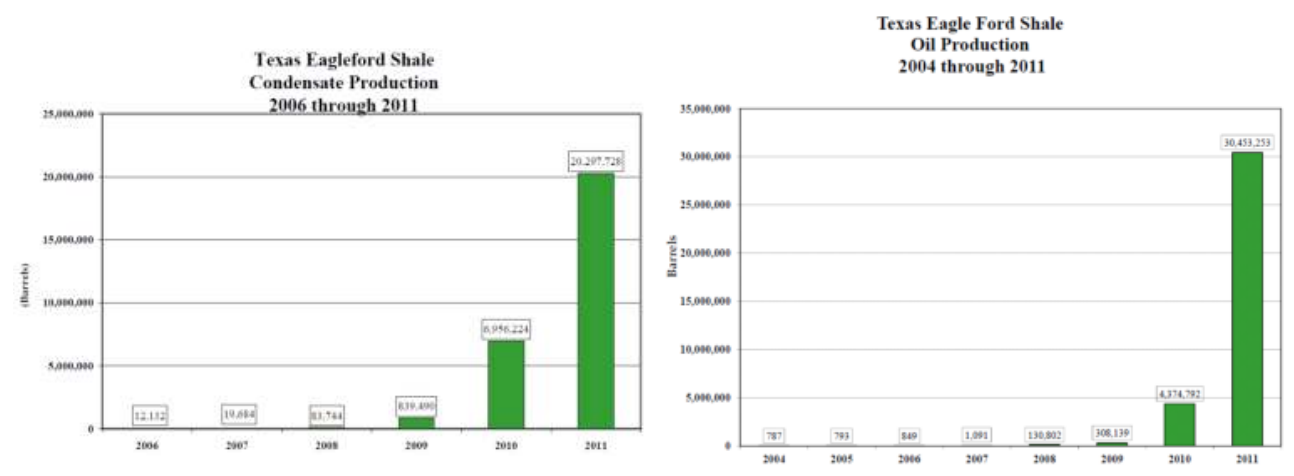

Figure 1. The phenomenal growth in production of liquids from shales with Eagle Ford. In just over a three-year period, insignificant production has been transformed to over 52 million barrels of liquids in 2011.

The growth in production is driven by improvements in hydraulic fracturing technology. Multistage fracturing using long horizontal wells is the common practice. Millions of gallons of water are pumped into the formation to create these fractures. Industry data reveals that only about a third of the injected water is typically recovered. The fate of injected water is of fundamental interest. Use of large quantities of water in fracturing has brought into question the sustainability of this type of completion and development practice. Furthermore, low water recovery has prompted environmental concerns about whether the injected water leaves the target formation with a potential of infiltrating and contaminating aquifers. The purpose of this paper was to examine the capability of the formation to imbibe the injected water based on different capillary pressure relationships.

\section{Technical approach}

The Advanced Reactive Transport Simulator (ARTS) at the University of Utah was used to perform simulation studies (Figure 2). ARTS is a modular reservoir simulator that has been under development over a number of years [2-4]. The main idea of ARTS is to decouple the discretization methods from the physical models. The discretization methods in ARTS include the conventional finite difference, control-volume finite element and a generalized control volume method. These discretization methods could be coupled with a variety of physical models. The simplest physical model would be simulation of a single-phase gas with immovable water phase. Two-phase and three-phase black oil models are used to simulate primary 
production followed by water and polymer flooding. Thermal processes such as steam flooding, in-situ combustion, steam-assisted gravity drainage, etc. are represented in K-value based thermal-compositional models. In these models, the vapor-liquid equilibrium is calculated using the ratio between the vapor and the liquid phase composition of each component (K-value). ARTS also includes a geochemical module to simulate processes associated with carbon dioxide sequestration and reactions involving carbon dioxide, brine and rocks.

The use of a control volume finite element model as one of the discretization schemes allows multiphase simulation of complex reservoir geometries including a discrete fracture network representation of natural and hydraulic fractures.

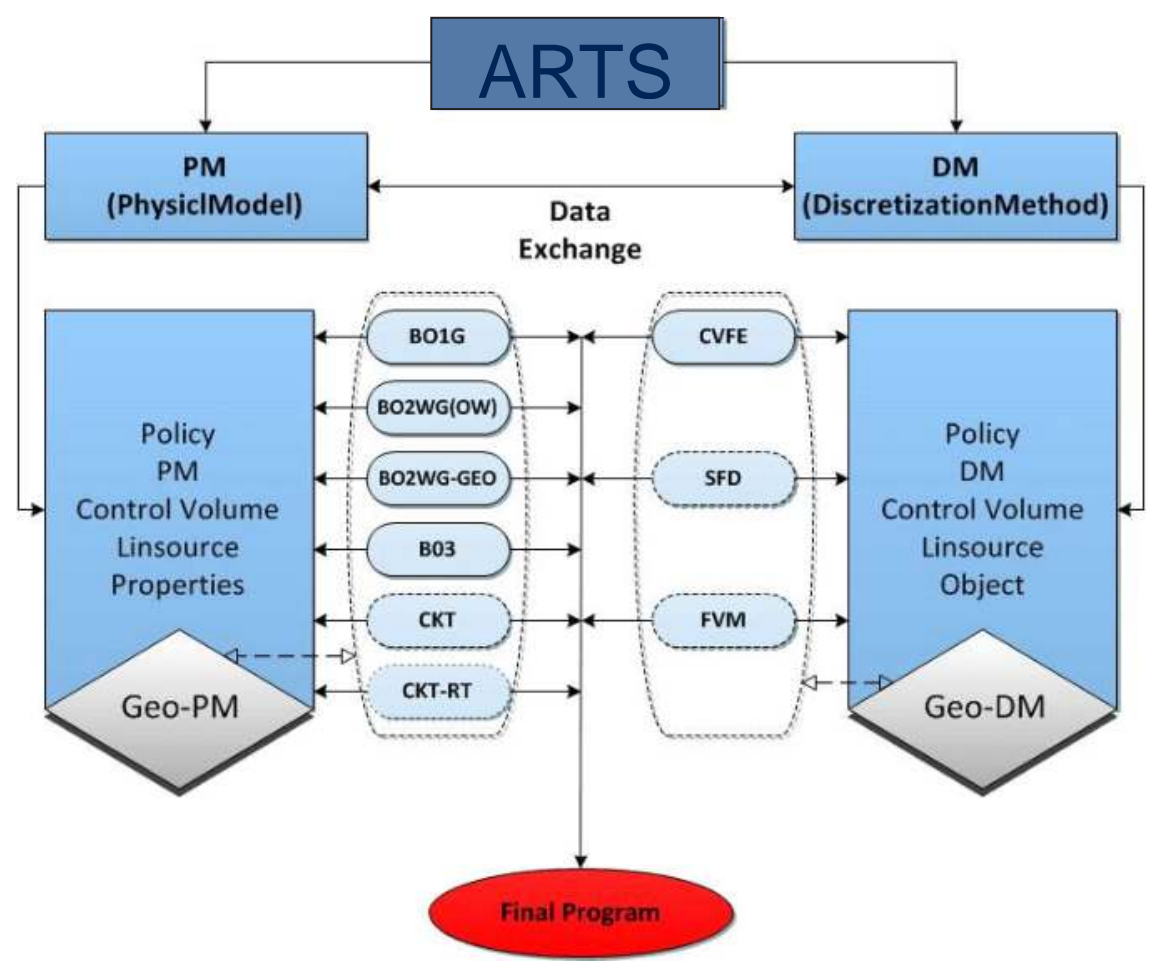

Figure 2. The framework used in simulating water injection and production in fractured systems. The discretization methods (DM) are decoupled from the physical models (PM).

We represented and simulated two different discrete fracture domains in this work - both with non-orthogonal features (Figure 3). It is common practice to represent and simulate hydraulic fractures as orthogonal features. However, it is evident that the fractures created are not perfectly perpendicular to the horizontal well. The microseimic cloud that is observed in a number of cases with multiple horizontal fractures (for example, [5]), shows fractures that are 
more complex than regularly spaced orthogonal features. It is true that there is no one to one correlation between the microseismic signatures and the shape and morphology of hydraulic fractures. However, there are a number of indications that point to the hydraulic fractures being more complex than simple orthogonal features.

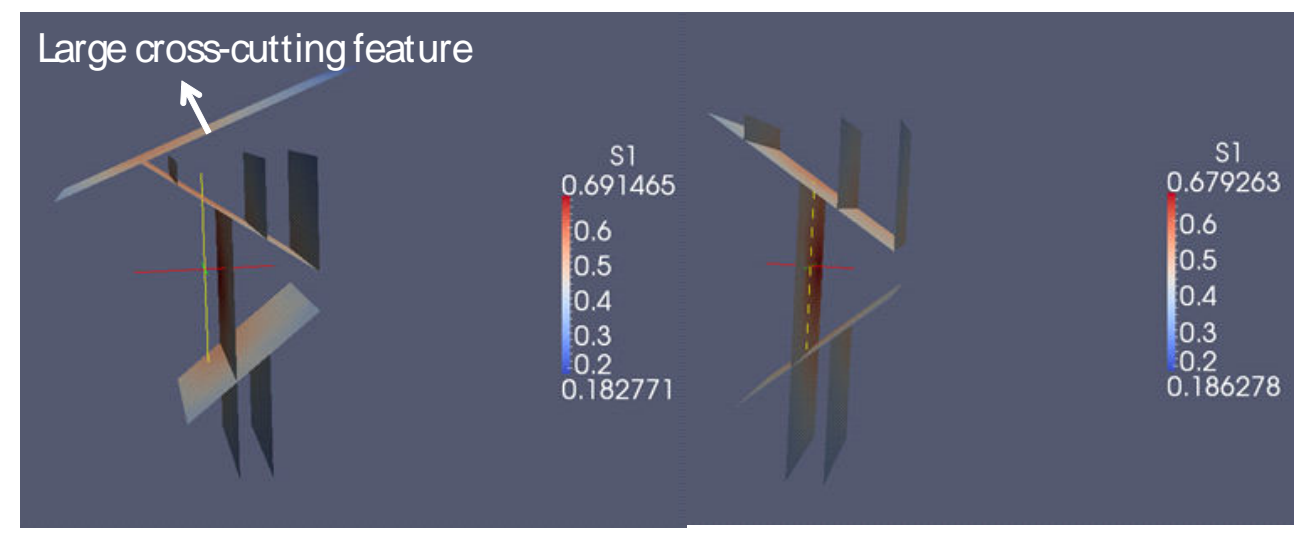

Figure 3. Figure showing two fractured systems simulated in this study.

The hydraulic fractures created interact with existing natural fractures. The role of natural fractures in production of fluids from shales is still an open question. The production behavior of both the gas and liquid reservoirs does not indicate a highly fractured system. On the other hand, when fracturing water is injected in a well, it is common to see interference in an adjacent well. This may be in the form of pressure interference or explicit breakthrough of water injected in the adjacent well. Pressure interference in and of itself does not indicate fluid transport to the well.

Capillary pressures for these shale reservoirs are not well characterized. The wettability of the reservoir rocks is also not well known. Al-Bazali et al. [6], measured sealing capacities of shale caprocks. This data provides some guidance for the capillary pressure values and relationships to use for these systems. The general capillary pressure relationship is given by:

$P_{c}=\frac{2 \sigma \cos \theta}{r}$

In this equation, $\mathrm{P}_{\mathrm{c}}$ is the capillary pressure, $\sigma$ is the interfacial tension between the immiscible fluids of interest, $\theta$ is the contact angle and $\mathrm{r}$ is the average pore radius. Al-Bazali et al.[6], were considering shales that were less than $10 \mathrm{nD}$ in permeability. For the three shales studied, they measured entry pressures ranging from 470 psia to 750 psia. They calculated pore throat radii of about $30 \mathrm{nM}$ for entry pressures of crude oil. For pore throats of less than $10 \mathrm{nM}$ (Sondergeld et al. [7]), very large capillary pressures (two to three times those measured by Al-Bazali et al [7]) are possible. 
There has been much discussion about wettability of shales. In this paper, we examined the differences in water recovery due to variations in wettability of the rock. The three sets of oilwater capillary pressures used in the study are shown in Figure 4.

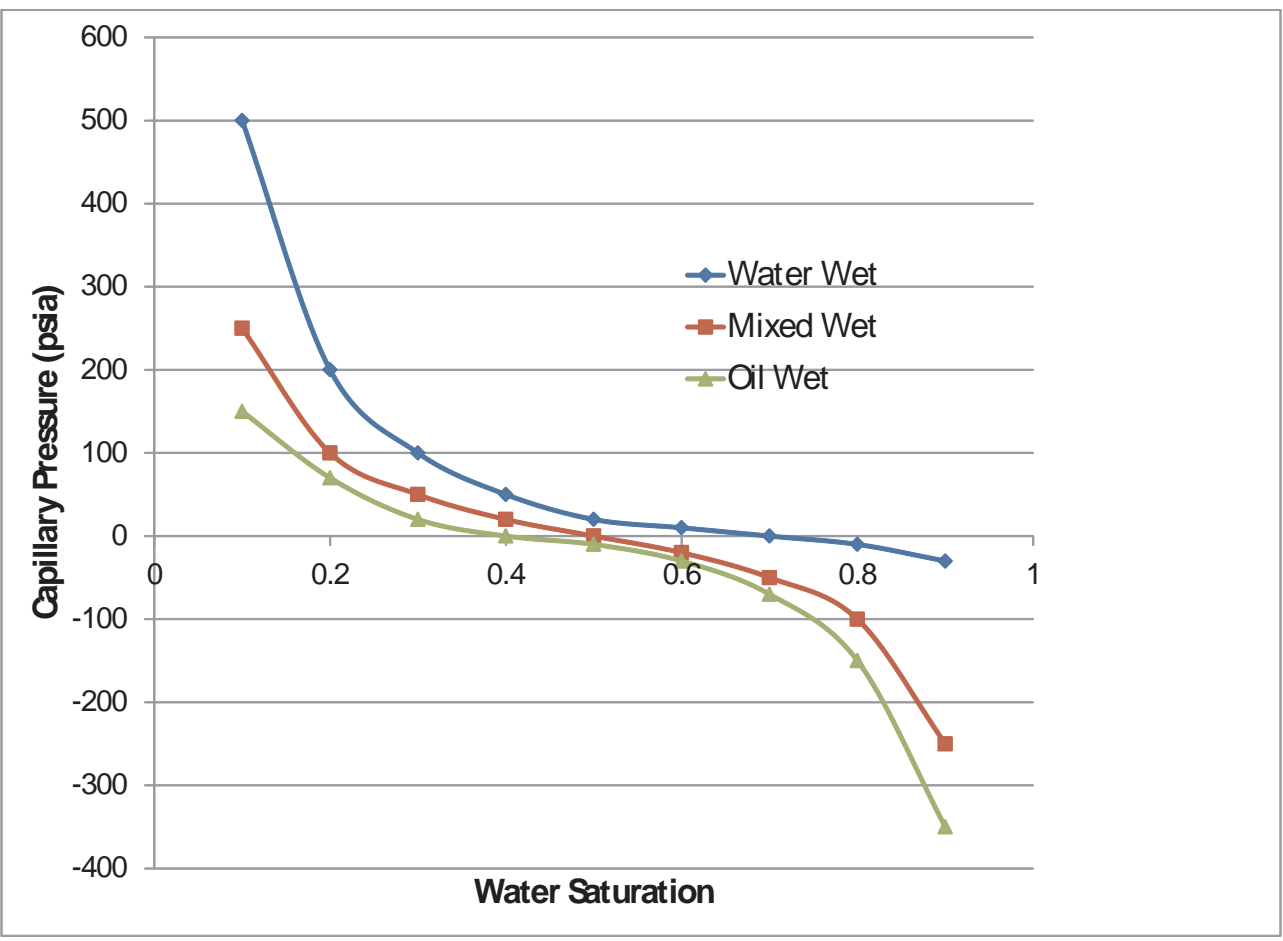

Figure 4. The three sets of capillary pressures used in this study.

Over most of the saturation range for the oil and mixed wet situations, the capillary pressures are negative, indicating a preference for oil as the wetting fluid. Other domain-specific parameters are shown in Table 1.

\begin{tabular}{ll}
\hline Domain Size & 260 feet $\times 260$ feet $\times 100$ feet \\
\hline Initial Reservoir Pressure & 2000 psia \\
\hline Fracture Permeability & $1000 \mathrm{mD}$ \\
\hline Porosity & $20 \%$ \\
\hline Matrix Permeability & $0.5 \mathrm{mD}$ \\
\hline Water Injected & 30000 barrels \\
\hline
\end{tabular}

Table 1. Properties of the domain and simulations 
Water recovery after one month (30 days) for each of the simulations was compiled. For the base case capillary pressures, the water recoveries for the three wetting scenarios and for the two domains (one with the cross-cutting fracture, and one without) are shown in Table 2.

\begin{tabular}{|c|c|c|c|}
\hline & Water Wet & Mixed Wet & Oil Wet \\
\hline $\begin{array}{l}\text { Water recovery ratio(With } \\
\text { cross-cutting fracture) }\end{array}$ & $21.53 \%$ & $29.35 \%$ & $36.28 \%$ \\
\hline $\begin{array}{l}\text { Water recovery ratio } \\
\text { (Without the cross-cutting } \\
\text { fracture) }\end{array}$ & $22.97 \%$ & $31.24 \%$ & $38.39 \%$ \\
\hline
\end{tabular}

Table 2. Water recoveries for the three wetting scenarios and for the two domains studied in this paper. Recoveries are for the base case where the initial reservoir pressure was 2000 psia and the matrix permeability was $0.5 \mathrm{mD}$.

The water recoveries observed in the table above are consistent with water recoveries of about $20-40 \%$ listed in field observations. Water recoveries increase as we go from water wet to mixed wet to oil wet clearly indicating the tendency of the matrix to imbibe and hold water as the formation becomes more water wet. There is a $15 \%$ increase in water recovery as we go from water wet to the oil wet case. The presence of the long cross-cutting feature does not make a significant impact in recovery. The recovery does decrease as injected water is transported to longer distances - but the difference in recovery is only $1-2 \%$.

In a number of shale reservoirs, the permeabilities are lower and the initial pressures are higher. To investigate the effects of these parameters on recovery, simulations were performed with 5000 psia initial pressure and $0.1 \mathrm{mD}$ matrix permeability. Results of these simulations are tabulated in Table 3.

\begin{tabular}{llll}
\hline & Water Wet & Mixed Wet & Oil Wet \\
\hline $\begin{array}{l}\text { Water recovery ratio(With } \\
\text { cross-cutting fracture) }\end{array}$ & $37.42 \%$ & $40.17 \%$ & $44.19 \%$ \\
\hline $\begin{array}{l}\text { Water recovery ratio } \\
\text { (Without the cross-cutting }\end{array}$ & $41.02 \%$ & $44.61 \%$ & $49.83 \%$ \\
fracture) & & & \\
\hline
\end{tabular}

Table 3. Water recoveries for the three wetting scenarios and for the two domains studied in this paper. Recoveries are for the base case where the initial reservoir pressure was 5000 psia and the matrix permeability was $0.1 \mathrm{mD}$.

Higher initial pressure results in higher water recoveries, particularly in the water wet cases. The differences between recoveries with and without the large cross-cutting feature are now between $4-5 \%$. The differences between the different wettability cases however are reduced to only about $8 \%$ (compared to about $15 \%$ ) as the largest difference the water wet and the oil wet scenarios. 
At smaller pore radii, the capillary pressures are expected to be larger. One set of simulations were performed where the shape of the base case capillary pressures were maintained, but the capillary pressures were increased ten times for each of the saturation values. The resulting recoveries are tabulated in Table 4.

\begin{tabular}{llll}
\hline & Water Wet & Mixed Wet & Oil Wet \\
\hline $\begin{array}{l}\text { Water recovery ratio(With } \\
\text { cross-cutting fracture) }\end{array}$ & $20.1 \%$ & $27.15 \%$ & $41.9 \%$ \\
\hline $\begin{array}{l}\text { Water recovery ratio } \\
\text { (Without the cross-cutting }\end{array}$ & $23.3 \%$ & $30.2 \%$ & $45.5 \%$ \\
fracture) & & & \\
\hline
\end{tabular}

Table 4. Water recoveries for the three wetting scenarios and for the two domains studied in this paper. Recoveries are for the case where the capillary pressures were ten times the base case capillary pressures used. The shapes of the capillary pressure curves were the same as the ones used in Figure 4. The initial reservoir pressure was 5000 psia and the matrix permeability was $0.1 \mathrm{mD}$.

As the capillary pressure increases, more water is retained. For mixed wet and oil wet scenarios, water saturation in the matrix area is lower (Figure 5). Similar relative difference between recoveries is maintained when recoveries are compared for domains with and without the large cross-cutting features. The system without the large cross-cutting fracture in this case returns on the average about $3 \%$ more water than when the large fracture exists. Water saturations for the domain without the large fracture are shown in Figure 6.

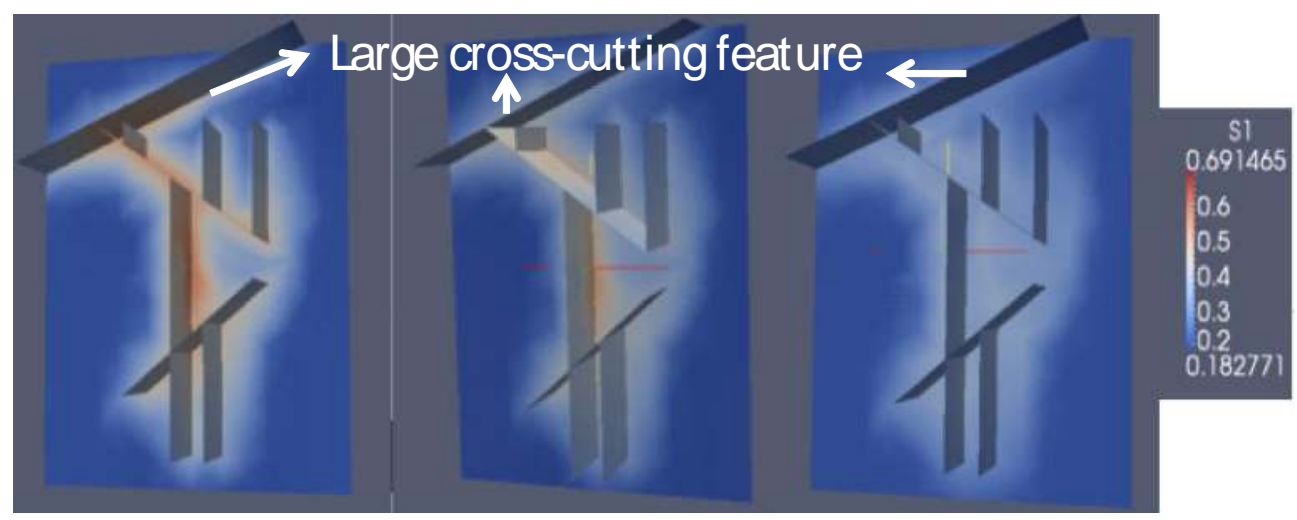

Figure 5. Figure showing water saturations in the matrix through one hydraulic fracture and interacting natural fractures. Left panel is for the water wet case, the middle panel is for the mixed wet case and the right panel is the oil wet case. As the wettability goes from water wet to oil wet the infiltration decreases increasing injected water recovery. In this particular example, the large cross-cutting feature does not take a significant amount of water off site. 


\section{Conclusions}

Recovery of water injected for hydraulic fracturing in shales is only about $30 \%$. There is a question of the fate of injected water. In this paper we studied water retention in shales for different shale wettability conditions. Two different domains where a hydraulic fracture intersected with a small existing network of natural fractures were used in the simulations. A specially developed framework that can handle representation of complex fracture networks was used for simulations. Capillary pressures in rocks containing very small pores tend to be high - of the order of 1000 psia. Three sets of capillary pressures - water wet, mixed wet and oil wet were examined. Simulations showed that a recovery of $20-30 \%$ is expected for typical water wet conditions, while a recovery of about $37 \%-48 \%$ is expected for oil wet scenarios. The recovery for mixed wet conditions fell between these two extremes. The recovery is reduced when a large cross-cutting fracture is introduced - but not significantly. That is because water will be recovered if the fractures are interconnected. Results discussed in this paper helped quantify the role of wettability in the recovery of water used for hydraulic fracturing. In this paper we assumed that the initial water saturation was low and that the water was immovable. If that is not the case, water saturation in the matrix and in the natural fractures, as well as the water-oil or water-gas relative permeability functions play significant roles in determining the water balance.

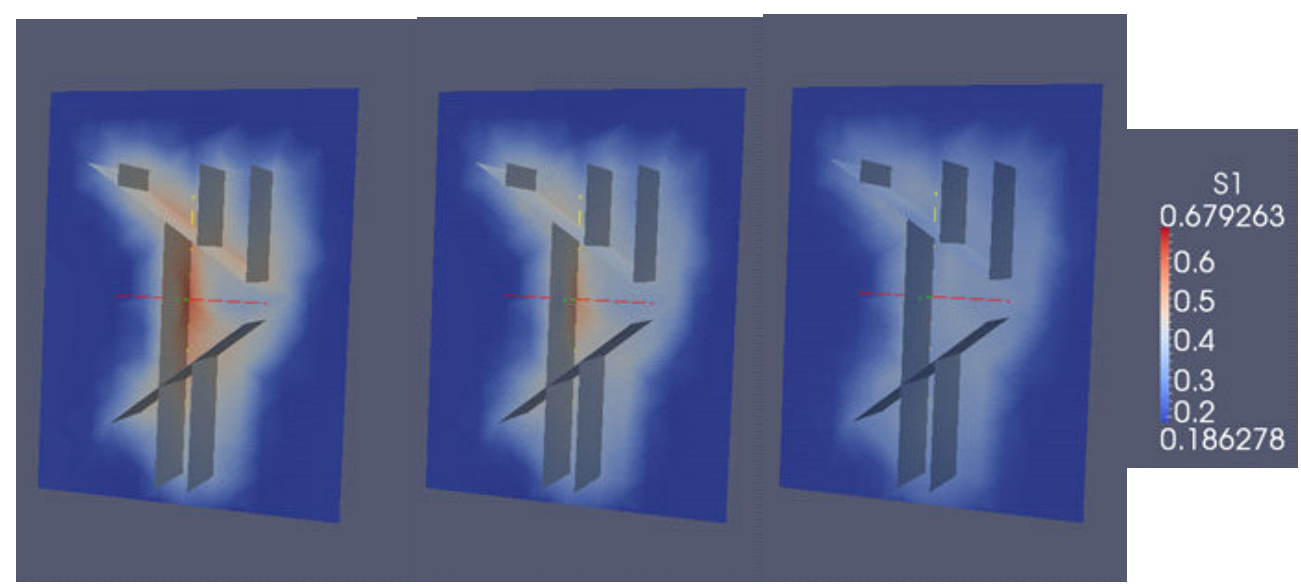

Figure 6. Figure showing water retained in the matrix through one hydraulic fracture and interacting natural fractures. Domain without the large cross-cutting feature is used. Left panel is for the water wet case, the middle panel is for the mixed wet case and the right panel is the oil wet case. Water saturation scale is also shown. As the wettability goes from water wet to oil wet the infiltration decreases increasing injected water recovery. 


\section{Author details}

Hongtao Jia, John McLennan and Milind Deo

Department of Chemical Engineering, University of Utah, Salt Lake City, UT, USA

\section{References}

[1] Data from the Texas Railroad Commission- http://wwwrrc.state.tx.us/

[2] Yang, Y. K. (2003). Finite-Element Multiphase Flow Simulator, Ph.D. dissertation, University of Utah, 2003.

[3] Fu, Y. (2007). Multiphase Control Volume Finite Element Simulation of Fractured Reservoirs, Ph.D. dissertation, University of Utah, 2007.

[4] Gu, Z. (2010). A Geochemical Compositional Simulator for Modeling C O2 Sequestration in Geological Formations, Ph.D. dissertation, University of Utah, 2010.

[5] Stegent, N. A, Ferguson, K, \& Spencer, J. (2011). Comparison of Frac Valves vs. Plug and Perf Completions in the Oil Segment of the Eagle Ford Shale: A Case Study, CSUG/ SPE 148642, Paper presented at the Canadian Unconventional Resources Conference, Calgary, Canada, November 2011., 15-17.

[6] Al-bazali, T. M, Zhang, J, Chenevert, M. E, \& Sharma, M. M. (2005). Measurement of the Sealing Capacity of Shale Caprocks, SPE 96100, Paper presented at the Annual Technical Conference and Exhibition, Dallas, Texas, Oct, 9-12.

[7] Curtis, M. E, Ambrose, R. J, Sondergeld, C. H, \& Rai, C. S. Structural Characterization of Gas Shales on the Micro- and Nano-scales, CSUG/SPE 137693, Paper presented at the Canadian Unconventional Resources and International Petroleum Conference held in Calgary, October (2010). , 19-21. 
